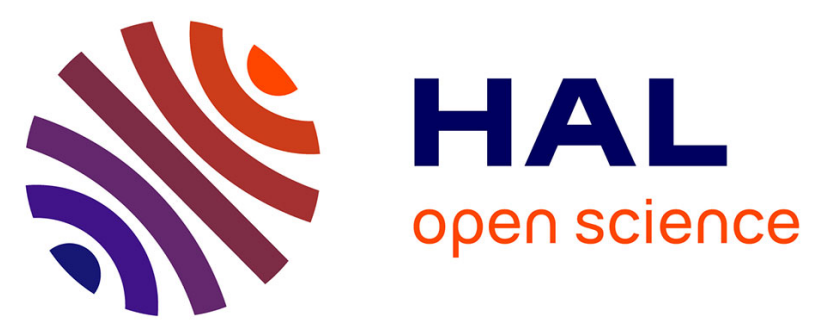

\title{
Combined theoretical and experimental studies of P3HT and PTB7 polymers for organic photodiodes
}

Léa Farouil, Fabienne Alary, Eléna Bedel-Pereira, Isabelle Séguy, Julien Roul, Corinne Routaboul, Victoria Shalabaeva, Gábor Molnár, Jean-Louis Heully

\section{- To cite this version:}

Léa Farouil, Fabienne Alary, Eléna Bedel-Pereira, Isabelle Séguy, Julien Roul, et al.. Combined theoretical and experimental studies of P3HT and PTB7 polymers for organic photodiodes. 11th IEEE Nanotechnology Materials and Devices Conference (NMDC 2016), Oct 2016, Toulouse, France. hal-01343979

\author{
HAL Id: hal-01343979 \\ https://hal.science/hal-01343979
}

Submitted on 11 Jul 2016

HAL is a multi-disciplinary open access archive for the deposit and dissemination of scientific research documents, whether they are published or not. The documents may come from teaching and research institutions in France or abroad, or from public or private research centers.
L'archive ouverte pluridisciplinaire HAL, est destinée au dépôt et à la diffusion de documents scientifiques de niveau recherche, publiés ou non, émanant des établissements d'enseignement et de recherche français ou étrangers, des laboratoires publics ou privés. 


\title{
Combined theoretical and experimental studies of P3HT and PTB7 polymers for organic photodiodes*
}

\author{
L. Farouil, F. Alary, E. Bedel-Pereira, I. Seguy, J. Roul, C. Routaboul, V. Shalabaeva, G. Molnar, J.L. \\ Heully
}

\begin{abstract}
The polymer PTB7 is used in a fluorescence detection system for fabricating a bulk heterojunction (BHJ) organic photodiode as a photodetector. It is chosen and studied theoretically because of its suitable absorption bandwidth and electron donor efficiency when associated with PCBM in BHJ. However, in order to be sure of our theoretical prediction, we validated our method on the well-known P3HT. This is done by investigating experimentally and theoretically the UV-vis, Raman and photoluminescence (PL) spectra. As our experimental and theoretical results are in perfect agreement, we are confident on the photophysical properties of PTB7 predicted by our method.
\end{abstract}

\section{INTRODUCTION}

In this work, a lab on a chip system based on micro-algae (Chlamydomonas reinhardtii) emission is investigated (see Fig. 1). The low band gap polymer, PTB7, is interesting for its optical properties especially for its absorption narrow bandwidth (550 - $750 \mathrm{~nm})$ [1] which corresponds perfectly to the algae emission $(650-750 \mathrm{~nm})$ [2] and furthermore has a high external quantum efficiency around $80 \%$ when it is mixed with [6, 6]-phenyl C71-butyric acid methyl ester (PC71BM) [3]. We perform TD-DFT and DFT calculations on the experimentally and theoretically extensively studied P3HT in order to identify the best-adapted simulation's methodology. Then we apply the same method on PTB7 in order to get a better understanding of the photophysical properties of this material.

\section{II.EXPERIMENTAL PART}

For experimental measurements, a Plexcore average Mn 54000 - 75000; >98\% head-to-tail regioregular (RR) P3HT

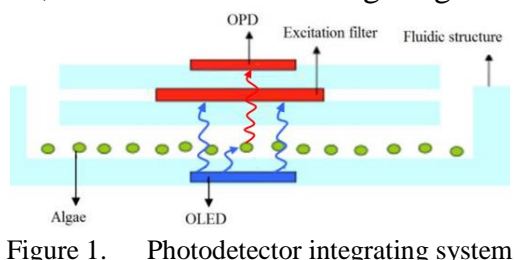

*This work was partly supported by LAAS-CNRS micro and nanotechnologies platform member of the French RENATECH network. This work was performed using HPC resources from CALMIP (Grant n'2011-P1133).

L. Farouil, E. Bedel-Pereira, I. Seguy and J. Roul are with LAAS-CNRS, Université de Toulouse, CNRS laboratory; CNRS; 7 avenue du Colonel ROCHE, F-31400 Toulouse, France (e-mail: lea.farouil@laas.fr). L. Farouil, F. Alary and J-L. Heully are with LCPQ-IRSAMC, Université de Toulouse, 118 route de Narbonne, F-31062 Toulouse, France. C. Routaboul, V. Shalabaeva and G. Molnar are with LCC laboratory; CNRS; 205 route de Narbonne, F-31077 Toulouse, France. and a PTB7 purchased from Sigma-Aldrich and 1-Material respectively were used. Solutions are prepared in a glove box and films are deposited by spin coating on Si substrates and thick indium tin oxide (ITO) covered glass substrates. P3HT properties were investigated by UV-Vis spectroscopy, Raman and photoluminescence (PL) measurements with an excitation at 784 and $488 \mathrm{~nm}$ respectively at low and room temperature (in the range $20-300 \mathrm{~K}$ for PL). The PTB7 chemical structure is shown in Fig. 2. Calculations were performed with ORCA [4] quantum package by using the B97-D functional in DFT approach. For the polymer, we choose a representative piece of a single chain, with $n$ from one to five for PTB7 and $\mathrm{n}$ equal to eight and ten for P3HT. To the best of our knowledge, it is the largest ab-initio calculation done on such large molecules.

\section{RESULTS AND DISCUSSION}

\section{A. P3HT experimental and theoretical comparison}

Fig. 3 shows the experimental and theoretical Raman spectra of RR-P3HT. Several Raman modes are observed; typically the main mode at $1445 \mathrm{~cm}^{-1}$ which is the symmetric $\mathrm{C}=\mathrm{C}$ stretch mode and at $1376 \mathrm{~cm}^{-1}$ the $\mathrm{C}-\mathrm{C}$ intraring stretch one. Others modes can be identified in agreement with those described in the literature $[5,6]$. As it is observed, most of the modes present a very good agreement. Considering that many studies of P3HT aggregation are done thanks to the Raman spectra, this agreement is quite encouraging for the rest of this study.

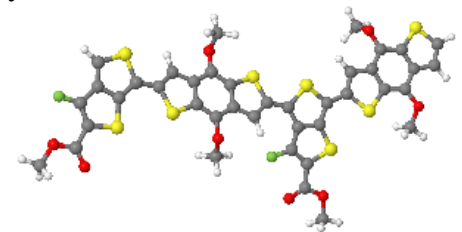

Figure 2. Modeling structure of PTB7 $(n=2)$

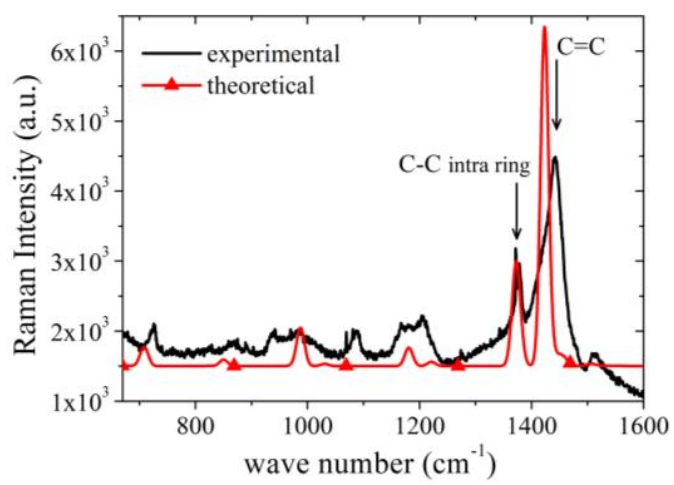

Figure 3. Experimental and theoretical Raman spectra of RR-P3HT. 
The low and room temperature absorption spectra of P3HT are reported in Fig. 4a. There is no significant change with the temperature increasing in our experimental spectra what is in agreement with Sundberg et al. [7]. However, experimental spectra are broader than theoretical ones. On the left part of the spectra, this is a physical effect which remains to be explained. However, on the right part of the spectra, this disagreement is mostly due to an artifact of our equipment. On Fig. 4b, theoretical and experimental PL spectra of P3HT are reported. Four peaks are distinguishable in each spectra and the distance between every maxima is the same for both spectra. The calculation and experiment seem to be even more similar in the PL case.

Fig. 5 represents the evolution of the intensity of these four maxima with temperature. As it is seen, peaks intensity decreases when temperature increases. This kind of temperature dependence of these intensities is scarcely done [6] but very informative.

In conclusion of this part, we can say that our methodology is perfectly able to reproduce all properties of interest for P3HT. Thus, we will use the same approach for the PTB7 starting by modeling the polymer with a chain from 1 unit to 5 units (183 atoms with 2200 orbitals).

\section{B. PTB7 theoretical analysis}

PTB7 calculations of the absorption and the emission, taking into account the vibrational motion, have been done. As can be seen in Fig. 6, there is still a small evolution (ca 0.1 $\mathrm{eV}$ ) between three and four polymers units. We can expect that the spectra will fully converge for the five units and that five units will be representative of the full polymer. However, comparison with experimental results obtained in solvent or in thin films, shows a shift of ca $0.4 \mathrm{eV}$, larger than for P3HT. Hence, we conclude that this molecule is certainly sensitive to its environment. For both spectra, we can see that the vibrations play an important role but compared to the $\mathrm{P} 3 \mathrm{HT}$ spectra, we can deduce that the geometrical variations, are less important in PTB7. One point should be stressed, in contrary to P3HT, the PTB7 tends to take a helicoidal geometry when adding units. Thus, the $\pi$ conjugation plays a less important role. A weak Stoke-shift can be observed which implies that ground and excited states have quite a similar geometry, in agreement with above vibrational analysis. Therefore, we can expect a very good fluorescence quantum yield which is, in fact, observed experimentally [3].
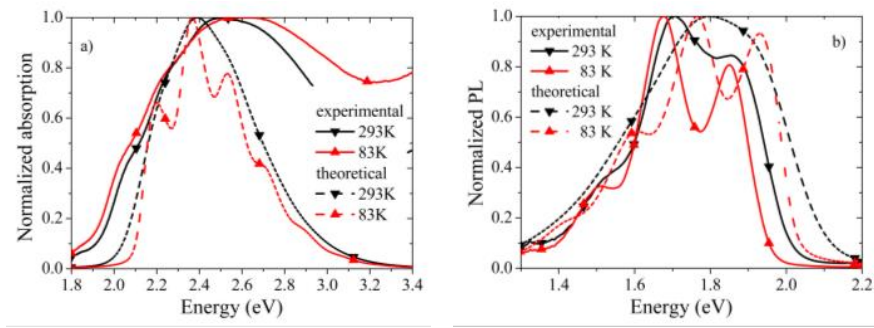

Figure 4. Theoretical resolved vibration and experimental relative a) absorption spectra and b) PL spectra at different temperatures of RR-P3HT.

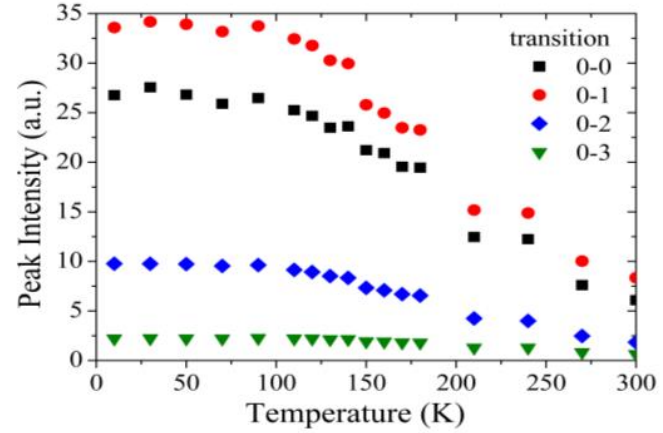

Figure 5. Temperature dependence of experimental intensity of $0-\mathrm{X}$ transitions. Transition $0-\mathrm{X}$ means transition between vibrational states of the ground state and the first excited state.

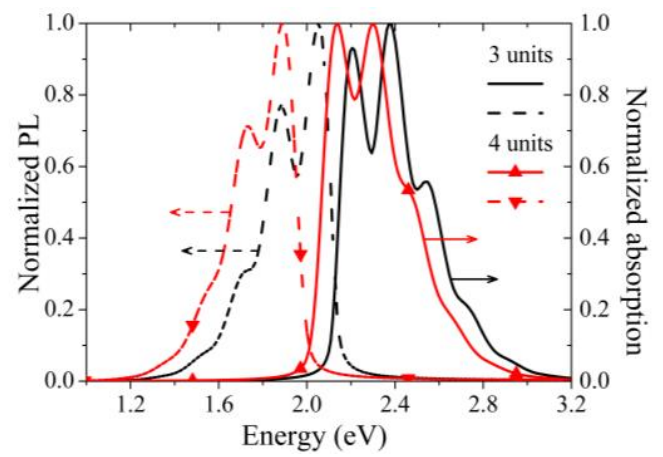

Figure 6. Theoretical resolved vibration relative absorption (straight line) and PL (dash line) spectra for a 3 (red curves) and 4 units (black curves) PTB7.

\section{CONCLUSION}

Thanks to the thorough comparison of experimental results with our theoretical protocol, we have obtained several conclusions. The DFT methodology is perfectly able to predict physical properties due to the fact that a sufficient number of units is taken; ten units for P3HT and at least five units for PTB7. Particularly, for PTB7, we have confirmed that a good fluorescence quantum yield is expected but absorption and PL are certainly sensitive to the environment. Furthermore, the polymer tends to adopt a helicoidal shape, which compared to P3HT, will change drastically the aggregation properties.

\section{REFERENCES}

[1]Y. Liang, Z. Xu, J. Xia, S. T. Tsai, Y. Wu, G. Li,C. Ray, and L. Yu, Adv. Mater., vol.22, p.E135-E138, 2010.

[2]F. Lefevre, A. Chalifour, L. Yu, V. Chodavarapu, P. Juneau, R. Izquierdo, Lab on a Chip, vol.12, p.787-793, 2012.

[3]C. M. Lochner, Y. Khan, A. Pierre and A. C. Arias, Nature communications, p.1-7, 2014

[4]F. Neese, ORCA-An Ab Initio, DFT and Semiempirical Program Package, version 3.0.3; University of Bonn: Bonn, Germany, 2012.

[5] W. C. Tsoi, D. T. James, J. S. Kim, P. G. Nicholson, C. E. Murphy, D. D. C. Bradley, J. Nelson, and J. Kim, J. Am. Soc., vol.133, p.9834-9843, 2011.

[6]P. J. Brown, D. S. Thomas, A. Köhler, J. S. Wilson, J.-S. Kim, C. M. Ramsdale, H. Sirringhaus, R. H. Friend, PHYSICAL REVIEW $B$ vol.67, p.064203, 2003.

[7]M. Sundberg, O. Inganäs, S. Stafström, G. Gustafsson, B. Sjögren, Solid State Communications, vol.71, p.435-439, 1989. 